\title{
S-quinolin-2-yl-methyldithiocarbazate-based magnetic adsorbent for magnetic solid-phase extraction of heavy metals from water samples
}

\author{
Ahmad Jazmi Abdul Rahman, How N.-F Fiona, Mohd Hamzah Mohd \\ Nasir, Sharifah Mohamad, Noorfatimah Yahaya, Maizatul Najwa Jajuli \& \\ Mazidatulakmam Miskam
}

To cite this article: Ahmad Jazmi Abdul Rahman, How N.-F Fiona, Mohd Hamzah Mohd Nasir, Sharifah Mohamad, Noorfatimah Yahaya, Maizatul Najwa Jajuli \& Mazidatulakmam Miskam (2019): S-quinolin-2-yl-methyldithiocarbazate-based magnetic adsorbent for magnetic solid-phase extraction of heavy metals from water samples, International Journal of Environmental Analytical Chemistry, DOI: $10.1080 / 03067319.2019 .1692827$

To link to this article: https://doi.org/10.1080/03067319.2019.1692827

曲 Published online: 26 Nov 2019.

Submit your article to this journal $₫$

Џ Article views: 12

Q View related articles $\square$

View Crossmark data ¿ 


\title{
S-quinolin-2-yl-methyldithiocarbazate-based magnetic adsorbent for magnetic solid-phase extraction of heavy metals from water samples
}

\author{
Ahmad Jazmi Abdul Rahman ${ }^{a}$, How N.-F Fiona ${ }^{b}$, Mohd Hamzah Mohd Nasir, \\ Sharifah Mohamade, Noorfatimah Yahaya (iD ${ }^{f}$, Maizatul Najwa Jajuli ${ }^{a}$ \\ and Mazidatulakmam Miskam ${ }^{\mathrm{a}}$ \\ aSchool of Chemical Sciences, Universiti Sains Malaysia, Penang, Malaysia; bepartment of Chemistry, \\ Kulliyyah of Science, International Islamic University Malaysia, Kuantan, Malaysia; 'Department of \\ Biotechnology, Kulliyyah of Science, International Islamic University Malaysia, Kuantan, Malaysia; ${ }^{\mathrm{d} C e n t r a l}$ \\ Research and Animal Facility (CREAM), Kulliyyah of Science, International Islamic University Malaysia, \\ Kuantan, Malaysia; 'Department of Chemistry, University of Malaya, Kuala Lumpur, Malaysia; ' Integrative \\ Medicine Cluster, Advanced Medical and Dental Institute (AMDI), Universiti Sains Malaysia, Bertam, Malaysia
}

\begin{abstract}
New S-quinolin-2-yl-methyl-dithiocarbazate-based magnetic adsorbent (MNP-SQ2MDTC) for magnetic solid phase extraction (MSPE) was developed for the determination of $\mathrm{Cd}^{2+}$ and $\mathrm{Cu}^{2+}$ in water samples. The surface of MNP was first coated with (3-aminopropyl) triethoxysilane (APTES) as cross-linker and then SQ2MDTC incorporated covalently to the coated MNP. The newly prepared MNPSQ2MDTC was analysed by Fourier Transform infrared (FT-IR), $\mathrm{X}$-ray diffractometer (XRD), energy dispersive X-ray spectroscopy (EDX), vibrating-sample magnetometry (VSM), field emission scanning electron microscopy (FESEM), transmission electron microscopy (TEM) and Brunauer-Emmett-Teller (BET). Under optimal MSPE conditions (20 mg adsorbent dispersed in $25 \mathrm{~mL}$ of sample which adjusted to $\mathrm{pH} 6.0$ and sonicated for $10 \mathrm{~min}$, before desorbed in $0.5 \mathrm{~mL}$ of $1 \mathrm{M} \mathrm{HClO}_{4}$ and sonicated for $5 \mathrm{~min}$ ), the validation method revealed a good linearity $\left(0.1-5.0 \mu \mathrm{g} \mathrm{mL}^{-1}\right)$ with the coefficient of determination $\left(R^{2}\right)$ in the range of $0.995-0.996$ for the samples. The limits of detection (LOD) of the developed method for $\mathrm{Cd}^{2+}$ and $\mathrm{Cu}^{2+}$ were found to be 0.054 and $0.040 \mathrm{\mu g} \mathrm{mL}^{-1}$, and limit of quantification (LOQ) were 0.180 and $0.134 \mu \mathrm{g} \mathrm{mL}^{-1}$, respectively. The recoveries of $\mathrm{Cd}^{2+}$ ranged from $75.6 \%$ to $93.9 \%$ and from $81.5 \%$ to $98.7 \%$ for $\mathrm{Cu}^{2+}$. To the best of our knowledge, this is the first study that have investigated the use of magnetic nanoparticles coated SQ2MDTC for determination of $\mathrm{Cd}^{2+}$ and $\mathrm{Cu}^{2+}$ in water samples analysis based on complexation of the metal ions to the surface of amino groups.
\end{abstract}

\section{ARTICLE HISTORY}

Received 21 August 2019

Accepted 8 November 2019

\section{KEYWORDS}

Magnetic nanoparticles; Squinolin2ylmethyldithiocarbazate; heavy metals removal; magnetic solid phase extraction

\section{Introduction}

Heavy metal pollution is one of the most severe environmental problems, that occurred from both natural and anthropogenic sources. Due to the potential adverse effects of 
these elements on humans, animals and ecosystems, the control and evaluation of the levels for different metals in diverse environmental, agricultural, food and clinical matrices are highly demanded by authorities and regulatory bodies [1,2]. For this reason, the development of sensitive and selective analytical procedures in order to determine metal ions have been a very active area of research.

Various methods have been applied for the heavy metal removals, such as electrochemical treatment technologies, membrane filtration, ion exchange, chemical precipitation and adsorption. Among the above methods, adsorption is considered as a highprofile method because of the considerable choice of adsorbent materials, operational ease and high efficiency [2-4]. However, the efficiency of adsorption processes relies on the performance of the adsorbents.

A wide variety of adsorbents have been applied to remove heavy metals, such as mesoporous silica [5,6], zeolites [7] and activated carbon [8]. However, these absorbents inherited some drawbacks such as poor adsorption capacity, tedious separation process and poor recycling stability.

In order to eliminate the inherited drawbacks, surface modification of magnetic nanoparticle (MNP) is the prerequisite. Recent researches in magnetic separation led to the development of new materials which mostly focusing on the magnetic materials containing a magnetite core coated with silica $\left(\mathrm{Fe}_{3} \mathrm{O}_{4} / \mathrm{SiO}_{2}\right)[9,10]$ or polymer $\left(\mathrm{Fe}_{3} \mathrm{O}_{4}\right.$ /polymer) $[7,11]$. The use of silica allows the introduction of the functional groups of interest, which is useful when surface changes are required. It increased the ease of modifying their surface functionality and their high surface area-to-volume ratio which can increase adsorption capacity and efficiency. MNP-based adsorbents can be easily recovered or manipulated from aqueous solutions under an external magnetic field due to their magnetic property. Hence, they have the advantages of simplicity, sensitivity and easy to operate in adsorption process $[12,13]$. They also have the potential to be used as a reusable adsorbent with convenient conditions. Although MNP-based adsorbents provide many advantages, they still suffer some drawbacks, i.e. sensitivity and selectivity. To overcome these limitations, intensive attempts have been made to improve the selectivity of magnetic adsorbents for the removal of heavy metals from environmental samples.

An extraction approach based on magnetic or magnetisable sorbents termed as magnetic solid-phase extraction (MSPE) was developed which is suitable for several analytes [14]. MSPE has vast advantages including ease of automation, high extraction efficiency and rapid phase separation [15]. It is one of the widely used methods currently due to its easiness, environmentally friendly and low cost [16]. Besides, no costly instrument or any type of device including column and cartridge is needed to operate MSPE, make it time-effective and easy to operate $[17,18]$. Recently, MSPE has been applied in various matrices for separation of pesticides [19-21], medicinal drugs [22,23], industrial chemicals [24,25] and dyes [26]. The use of MNP for the development of MSPE has become increasingly popular due to the advantages of easy control and simple separation.

A considerable interest has been shown in metal complexes of dithiocarbazate derivatives [27-29]. S-alkyl or aryl dithiocarbazates constitutes one of the most important classes of mixed hard-soft nitrogen-sulphur donor ligands [30], having four potential donor atoms of which two are sterically available at a time to chelate metal ions. In fact, the presence of hard nitrogen and soft sulphur atoms enable these ligands to react with both transition and main group metals [31]. Dithiocarbazate derivatives interact with 
metal ions to give structures of different geometry and properties and they are often biologically active [32]. Different substitutions of S-alkyl and aryl dithiocarbazate have been explored such as S-methyldithiocarbazate and S-benzyldithiocarbazate. Many reports have been published on the successful formation of mentioned ligand, complexed with metals such as $\mathrm{Ni}(\mathrm{II})[33,34], \mathrm{Cu}(\mathrm{II})[35,36], \mathrm{Cd}(\mathrm{II})[27,37], \mathrm{Pb}$ (II) [38] and $\mathrm{Hg}(\mathrm{II})$ [39]. Despite their excellent biological activities, the ability to form stable complexes with metal signifies great potential to be used for heavy metal removal.

In this work, MNP modified with S-quinolin-2-yl-methyldithiocarbazate (SQ2MDTC) was designed for the adsorption of $\mathrm{Cu}^{2+}$ and $\mathrm{Cd}^{2+}$ as the model metals. The aim of this study is to prepare selective and sensitive magnetic adsorbents with excellent adsorption capacity with high magnetisation for easy regeneration. The influences of adsorption $\mathrm{pH}$, adsorbent weight, sonication time, sample volume, type of eluent and eluent volume on the extraction capacity of the synthesised adsorbent were evaluated and discussed. The structure and surface properties of optimum MNP-SQ2MDTC were characterised.

\section{Experimental}

\subsection{Chemicals and reagents}

All chemicals and solvents used were of analytical reagent grade unless stated otherwise. Iron(III) chloride hexahydrate $\left(\mathrm{FeCl}_{3} \cdot 6 \mathrm{H}_{2} \mathrm{O}\right)$, ammonium iron(II) sulphate hexahydrate $\left(\left(\mathrm{NH}_{4}\right)_{2} \mathrm{Fe}\left(\mathrm{SO}_{4}\right)_{2} \cdot 6 \mathrm{H}_{2} \mathrm{O}\right)$, ammonia solution $\left(\mathrm{NH}_{3}\right)(28 \%)$, dichloromethane $\left(\mathrm{CH}_{2} \mathrm{Cl}_{2}\right)$ and nitric acid $\left(\mathrm{HNO}_{3}\right)$ (65\%) were purchased from QRëC ${ }^{\circledast}$ (Selangor, Malaysia). Potassium carbonate $\left(\mathrm{K}_{2} \mathrm{CO}_{3}\right)$ and 3-aminopropyl triethoxysilane (APTES) was purchased from SigmaAldrich (USA). Carbon disulphide $\left(\mathrm{CS}_{2}\right)$ were obtained from Merck KGaA (Darmstadt, Germany). Hydrazine hydrate $\left(\mathrm{NH}_{2} \mathrm{NH}_{2} \cdot \mathrm{H}_{2} \mathrm{O}\right)(80 \%$ in water for synthesis) was obtained from Merck (Hohenbrunn, Germany). 2-chloromethylquinoline hydrochloride $\left(\mathrm{C}_{10} \mathrm{H}_{8}\right.$ $\mathrm{CIN} \cdot \mathrm{HCl}$ ) was purchased from Tokyo Chemical Industry Co., Ltd. (TCl) (Tokyo, Japan). Potassium hydroxide was purchased from Fisher Scientific (UK). Ethanol $\left(\mathrm{CH}_{3} \mathrm{CH}_{2} \mathrm{OH}\right)$ (absolute, denatured) which obtained from HmbG (Hamburg, Germany) was diluted to $40 \%, 80 \%$ and $90 \%$ for synthesis of SQ2MDTC. Dry toluene was prepared by adding $4 \AA$ molecular sieves (Sigma-Aldrich, Inc., USA) into toluene $\left(\mathrm{C}_{6} \mathrm{H}_{5} \mathrm{CH}_{3}\right)\left(\mathrm{QRëC^{ \circledR }}\right.$, Selangor, Malaysia) at least $24 \mathrm{~h}$ before use.

\subsection{Instrumentations}

Fourier Transform-infrared (FT-IR) spectra were recorded using PerkinElmer Series 2000 FTIR spectrometer (USA) in the range of $400-4000 \mathrm{~cm}^{-1}$. For the structural analysis, the XRD pattern was recorded using a monochromatised $X$-ray beam with nickel-filtered $\mathrm{Cu} K a$ radiation $(\lambda=1.5419 \AA$ ) at $40 \mathrm{~mA}$ and $40 \mathrm{kV}$ on PANalytical X'Pert PRO MRD PW3040 X-ray diffractometer system (Almelo, Netherlands). The magnetic properties of the magnetic nanoparticles were determined using Lake Shore 7400 Series vibrating sample magnetometer system (USA). Quanta ${ }^{\text {TM }} 650$ FEG scanning electron microscope (SEM) (FEl, Holland) and Carl Zeiss energy filter transmission electron microscope (EFTEM) Libra ${ }^{\circledR} 120$ (Oberkochen, Germany) were used to observe the size, morphology and structure of the nanoparticles. The surface area and pore size distribution of the MNP-SQ2MDTC were 
measured by nitrogen adsorption-desorption isotherms at $77 \mathrm{~K}$ on Micromeritics ASAP 2020 (USA) using Brunauer-Emmett-Teller (BET) desorption methods. The magnetic solid phase extraction studies were performed on atomic adsorption spectrometer (AAS) (PerkinElmer AAnalyst ${ }^{\mathrm{TM}}$ 400, USA) and inductively coupled plasma-optical emission spectrometer (ICP-OES) (PerkinElmer Optima ${ }^{\mathrm{TM}}$ 8000, USA).

\subsection{Preparation of magnetic adsorbents}

\subsubsection{Synthesis of $\mathrm{Fe}_{3} \mathrm{O}_{4}$ magnetic nanoparticles ( $\mathrm{MNP}-\mathrm{Fe}_{3} \mathrm{O}_{4}$ )}

MNP- $\mathrm{Fe}_{3} \mathrm{O}_{4}$ were prepared by co-precipitation method according to method done by Ali et al. [10] with minor modifications. $9.6 \mathrm{~g} \mathrm{FeCl}_{3} \cdot 6 \mathrm{H}_{2} \mathrm{O}$ and $4.8 \mathrm{~g}\left(\mathrm{NH}_{4}\right)_{2} \mathrm{Fe}\left(\mathrm{SO}_{4}\right)_{2} \cdot 6 \mathrm{H}_{2}$ $\mathrm{O}$ (ratio 2:1) were added to $120 \mathrm{~mL}$ distilled water under nitrogen atmosphere and then stirred for $5 \mathrm{~min}$ at $60^{\circ} \mathrm{C}$. Then, $90 \mathrm{~mL}$ of ammonia solution $(8 \mathrm{M})$ was added dropwise into the reaction mixture. A black precipitate was formed immediately, and the reaction was allowed to proceed for another one hour. Then, by using an external magnet, MNP- $\mathrm{Fe}_{3} \mathrm{O}_{4}$ was collected before it was washed with excess doubly hot distilled water until neutral $\mathrm{pH}$ was obtained. Finally, the product was dried under vacuum at $60^{\circ} \mathrm{C}$ for $24 \mathrm{~h}$.

\subsubsection{Synthesis of silica core-shell magnetic nanoparticles (MNP-APTES)}

Silica core-shell $\mathrm{Fe}_{3} \mathrm{O}_{4}$ MNP were done in the same manner as previously reported by Rajabi et al. [40]. First, $5 \mathrm{~g}$ of freshly prepared $\mathrm{Fe}_{3} \mathrm{O}_{4} \mathrm{MNP}$ and $20 \mathrm{~mL}$ of dry toluene were sonicated for $30 \mathrm{~min}$. Then, $4.68 \mathrm{~mL}$ APTES reagent was added to the sonicated mixture and stirred under nitrogen atmosphere at $60^{\circ} \mathrm{C}$ for $12 \mathrm{~h}$. After that, the mixture was cooled down before the precipitates were magnetically separated and washed with dry toluene and water-acetone mixture $(20: 80 \% \mathrm{v} / \mathrm{v})$. The functionalised $\mathrm{Fe}_{3} \mathrm{O}_{4}$ MNP will further be dried under vacuum for $24 \mathrm{~h}$ at ambient temperature.

\subsubsection{Synthesis of S-quinolin-2-yl-methyldithiocarbazate (SQ2MDTC)}

$70 \mathrm{~mL}$ of $90 \%$ ethanol was filled in a beaker before $0.4 \mathrm{~mol}$ of potassium hydroxide was dissolved and mixed with $0.2 \mathrm{~mol}$ of hydrazine hydrate. The mixture was then placed in an ice salt bath to cool to $0^{\circ} \mathrm{C}$. Carbon disulphide $(0.2 \mathrm{~mol})$ was added dropwise with temperature below $-8^{\circ} \mathrm{C}$ and constantly stirred for about $1 \mathrm{~h}$. Two layers were formed from the reaction and separated in different beakers. Then, $60 \mathrm{~mL}$ of $40 \%$ ethanol was added to the lower layer of brown oil. The mixture was then kept in an ice bath. 2-chloromethylquinoline hydrochloride $(0.2 \mathrm{~mol})$ was dissolved in $80 \mathrm{~mL}$ of $80 \%$ ethanol before added dropwise to the mixture with vigorous stirring. A cream-coloured product which is S-quinolin-2-yl-methyl-dithiocarbazate will be formed. The product was filtered, recrystallised with ethanol and dried in vacuo over silica gel.

\subsubsection{Synthesis of MNP functionalised with S-quinolin-2-yl-methyldithiocarbazate (MNP-SQ2MDTC) adsorbent}

MNP-SQ2MDTC was prepared according to a method previously reported by Mohammadi et al. [41]. About $1 \mathrm{~g}$ of MNP-APTES and $0.07 \mathrm{~g}$ potassium carbonate was dispersed in $50 \mathrm{~mL}$ dry toluene and mechanically stirred for $30 \mathrm{~min}$. Subsequently, $1 \mathrm{~g}$ of SQ2MDTC was added and was kept under mechanical stirring at $60^{\circ} \mathrm{C}$ for $24 \mathrm{~h}$. Then, the final 
product was removed by magnetic decantation and washed twice by dry dichloromethane and water, respectively, to remove the unattached substrates. The product was dried under vacuum for $24 \mathrm{~h}$ at ambient temperature and kept over the silica gel.

\subsection{Magnetic solid phase extraction (MSPE) procedure}

A portion of sample containing the analyte ions was transferred into a $50 \mathrm{~mL}$ beaker and adjusted to $\mathrm{pH} 6.0$ with $0.1 \mathrm{~mol} \mathrm{~L}^{-1} \mathrm{HNO}_{3}$ and $0.1 \mathrm{~mol} \mathrm{~L}^{-1}$ aqueous ammonia. Then, $20 \mathrm{mg}$ of MNP-SQ2MDTC were added and dispersed by ultrasonication for $10 \mathrm{~min}$ at room temperature to facilitate the metal ions adsorption process. A strong external magnet was used to separate the magnetic adsorbent and the supernatants were decanted. Next, $0.5 \mathrm{~mL}$ of $1.0 \mathrm{~mol} \mathrm{~L}^{-1}$ perchloric acid was used to desorb the adsorbed analytes from the isolated adsorbent and sonicated for $5 \mathrm{~min}$. Finally, the adsorbent was separated by external magnet again and the eluate was introduced into AAS for subsequent analysis.

\subsection{Method validation}

To validate the developed MSPE method, its linearity, precision, limit of detection (LOD), limit of quantification (LOQ) and accuracy were studied under optimised conditions. The linearity was determined through the standard curves of working solutions at concentration ranging between $0.1 \mu \mathrm{g} \mathrm{mL}^{-1}$ to $5 \mu \mathrm{g} \mathrm{mL}^{-1}$. Each sample was prepared by diluting the standard solution of specific metal ion with deionised water and was examined by triplicate analysis. The calibration curves were prepared using five spiking levels of analytes.

LOD was calculated according to IUPAC definition where the limit of detection is equal to three times of standard deviation and divided by the slope of method calibration curve $\left(\mathrm{LOD}=3 \times \mathrm{SD}_{\text {blank }} / m, n=3\right)$. For the limit of quantification, it was 10 times of standard deviation and divided by the slope of method calibration curve (LOQ $=10 \times \mathrm{SD}_{\text {blank }}$ $/ m, n=3$ ).

The assessment of precision expressed as relative standard deviation (RSD) was done in term of repeatability (intra-day) and reproducibility (inter-day). The intra-day precisions were calculated from six parallel procedures performed in a single day, while the inter-day precisions were measured over three consecutive days.

\subsection{Real sample analysis}

The performance of proposed method has been investigated by applying in real water samples collected from various local rivers. The obtained samples were filtered through filter paper and adjusted to $\mathrm{pH} 6.0$ with $0.1 \mathrm{~mol} \mathrm{~L}^{-1} \mathrm{HNO}_{3}$ and $0.1 \mathrm{~mol} \mathrm{~L}^{-1}$ aqueous ammonia. Then, unspiked and spiked samples $\left(0.1 \mu \mathrm{g} \mathrm{mL}^{-1}\right.$ for $\mathrm{Cu}^{2+}$ and $1.0 \mu \mathrm{g} \mathrm{mL}^{-1}$ for $\mathrm{Cd}^{2+}$ ) were prepared before metal ions were extracted using synthesised adsorbent in optimised MSPE conditions. The eluents were analysed using ICP-OES in triplicate measurements. 


\section{Results and discussion}

\subsection{Synthesis of MNP functionalised with S-quinolin-2-yl-methyldithiocarbazate} (MNP-SQ2MDTC) adsorbent

In this study, MNP-SQ2MDTC has been successfully synthesised prior to complex formation with heavy metals. As illustrated in Figure 1, core-shell structured $\mathrm{Fe}_{3} \mathrm{O}_{4}-\mathrm{SQ} 2 \mathrm{MDTC}$ composites were readily prepared and subsequently employed to form complex with heavy metals. In the first step, the chemical co-precipitation of $\mathrm{Fe}^{2+}$ and $\mathrm{Fe}^{3+}$ ions in ammonia solution afforded the magnetite nanoparticles. The co-precipitation process was carried out in a nitrogen atmosphere at $60^{\circ} \mathrm{C}$ to avoid the oxidation of the magnetic
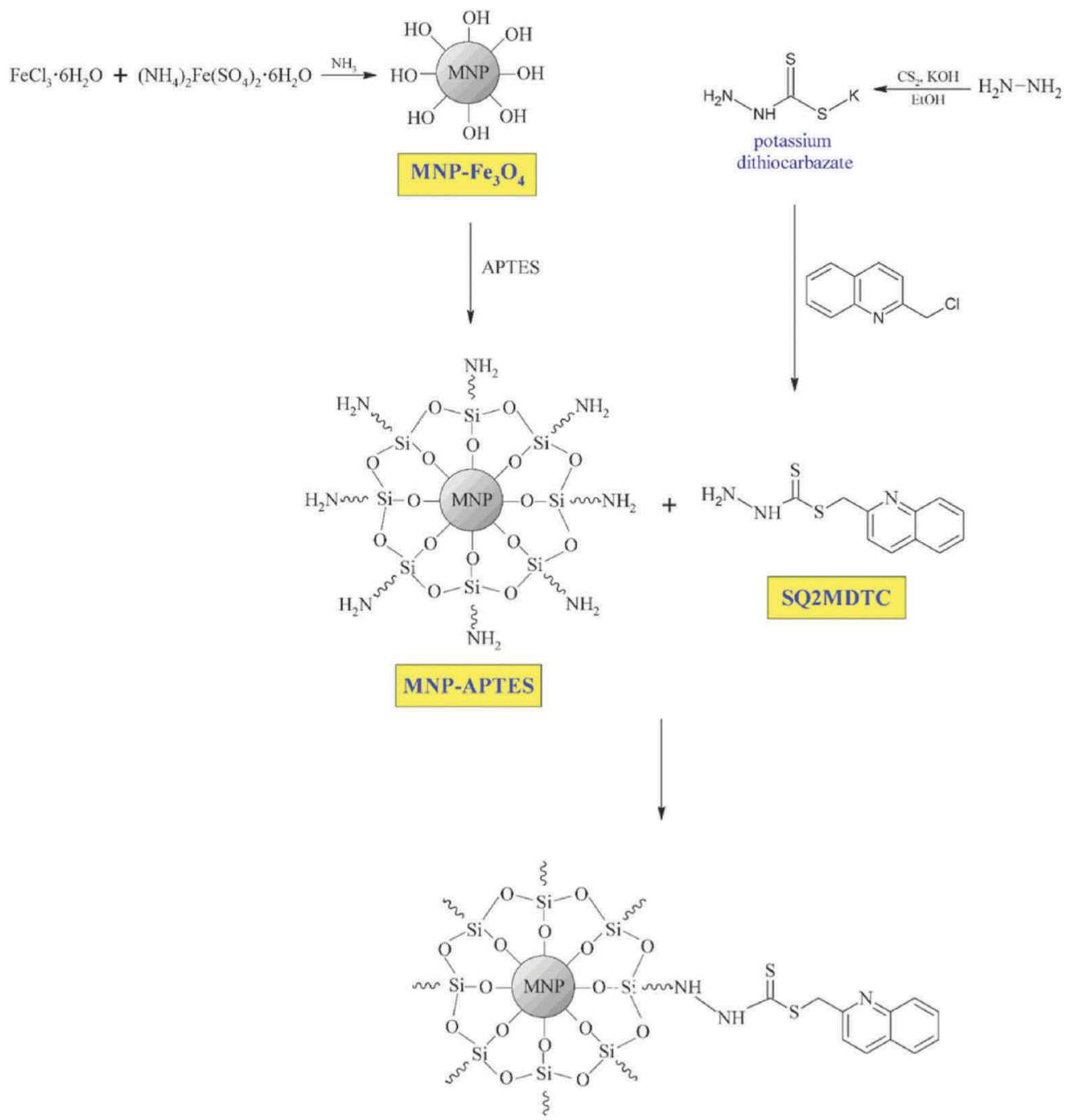

MNP-SQ2MDTC

Figure 1. Schematic of the synthesis of MNP-SQ2MDTC. 
core shell. Immediately after the completion of the process, an aqueous solution of ammonia was added in order to precipitate and produce MNP.

The SQ2MDTC ligand was synthesised by the addition of hydrazine hydrate and carbon disulphide in ethanolic potassium hydroxide at $0^{\circ} \mathrm{C}$. Two distinctive layers were formed and separated to obtain the lower brown layer of potassium dithiocarbazate. Then, chloromethylquinoline hydrochloride was added and the positive-charged potassium on potassium dithiocarbazate was substituted with chloromethylquinoline to form cream colour SQ2MDTC precipitate. The ligand was prepared with several modifications to optimise the yield as compared to the work previously reported by How et al. [30]. The concentration of potassium hydroxide has been doubled to increase the basicity of the solution which will increase the reaction rate between hydrazine hydrate and carbon disulphide to form potassium dithiocarbazate.

APTES was added to the MNP in order to reduce the agglomeration and as crosslinker to provide active site for SQ2MDTC attachment. SQ2MDTC possesses both hard nitrogen and soft sulphur donor atoms; hence, it can bind either with hard atoms or soft atoms $[33,42,43]$. In addition, MNP-APTES can be classified as 'hard' due to abundance of oxygen and silica atoms on its surface. Thus, theoretically, nitrogen atom of SQ2MDTC is more favourable to bind with MNP-APTES since hard atom will only bind with other hard atoms. Potassium carbonate $\left(\mathrm{K}_{2} \mathrm{CO}_{3}\right)$ was used in the synthesis of MNP-SQ2MDTC to activate MNP-APTES and improve the conjugation process of SQ2MDTC to MNP [44].

\subsection{Characterisation of MNP-SQ2MDTC}

\subsubsection{FT-IR analysis}

The FTIR spectra for the prepared magnetic adsorbents are shown in Figure 2. For $\mathrm{Fe}_{3} \mathrm{O}_{4}$ magnetic nanoparticles (Figure 2(a)), a stretching vibration at $3392 \mathrm{~cm}^{-1}$ was assigned for the $\mathrm{O}-\mathrm{H}$ bonds on the surface iron atoms. The bands at low wave numbers $\left(\leq 700 \mathrm{~cm}^{-1}\right)$ signified the vibrations of $\mathrm{Fe}-\mathrm{O}$ bonds of iron oxide, $\mathrm{Fe}_{3} \mathrm{O}_{4}$, in which the peaks at 634 and $583 \mathrm{~cm}^{-1}$ were assigned to the $\mathrm{Fe}^{3+}-\mathrm{O}-\mathrm{Fe}^{3+}$ and $\mathrm{Fe}^{2+}-\mathrm{O}-\mathrm{Fe}^{2+}$ symmetrical stretching vibrations, respectively. It should be pointed out that the band around $1624 \mathrm{~cm}^{-1}$ was attributed to the bending vibration of $\mathrm{H}-\mathrm{O}-\mathrm{H}$ linkage of water in the $\mathrm{Fe}_{3} \mathrm{O}_{4}$ nanoparticles.

The introduction of APTES coating on the surface of MNP was confirmed by the existence of several bands in the spectrum of MNP-APTES (Figure 2(b)). The bands at 1110 and $1021 \mathrm{~cm}^{-1}$ were assigned to $\mathrm{SiO}-\mathrm{H}$ and $\mathrm{Si}-\mathrm{O}-\mathrm{Si}$ groups. The bands at 893 and $798 \mathrm{~cm}^{-1}$ were ascribed as the stretching $\mathrm{Si}-\mathrm{O}-\mathrm{H}$ and vibration of $\mathrm{OH}$ on the surface of MNP. The broad bands at 1620 and $3406 \mathrm{~cm}^{-1}$ were assigned to $\mathrm{N}-\mathrm{H}$ stretching vibration and bending mode of free $-\mathrm{NH}_{2}$ group, respectively. The appearance of two bands at 2926 and $2853 \mathrm{~cm}^{-1}$ indicated the symmetric and asymmetric $\mathrm{C}-\mathrm{H}_{2}$ stretching vibration, respectively, which confirmed the anchoring of propyl group on the surface of MNP.

For SQ2MDTC spectrum (Figure 2(c)), a sharp band at $3283 \mathrm{~cm}^{-1}$ is the most significant as it indicates the presence of $\mathrm{N}-\mathrm{H}$ bond. $\mathrm{NH}_{2}$ rocking mode can also be found at $1049 \mathrm{~cm}^{-1}$, while $\mathrm{NH}_{2}$ stretching band can be found at $972 \mathrm{~cm}^{-1}$. Bands at $762 \mathrm{~cm}^{-1}$, $476 \mathrm{~cm}^{-1}$ and $437 \mathrm{~cm}^{-1}$ were assigned as bending $\mathrm{N}-\mathrm{C}-\mathrm{S}$ [32]. The medium band at $995 \mathrm{~cm}^{-1}$ is due to - CSS stretching vibration. The C-S band can be found at $828 \mathrm{~cm}^{-1}$. For the aryl group, bands between 1400 and $1650 \mathrm{~cm}^{-1}$ have been assigned to $C-C$ and $\mathrm{C}=\mathrm{C}$ stretching modes. The observed stretching band appeared at $1566 \mathrm{~cm}^{-1}$ has been 


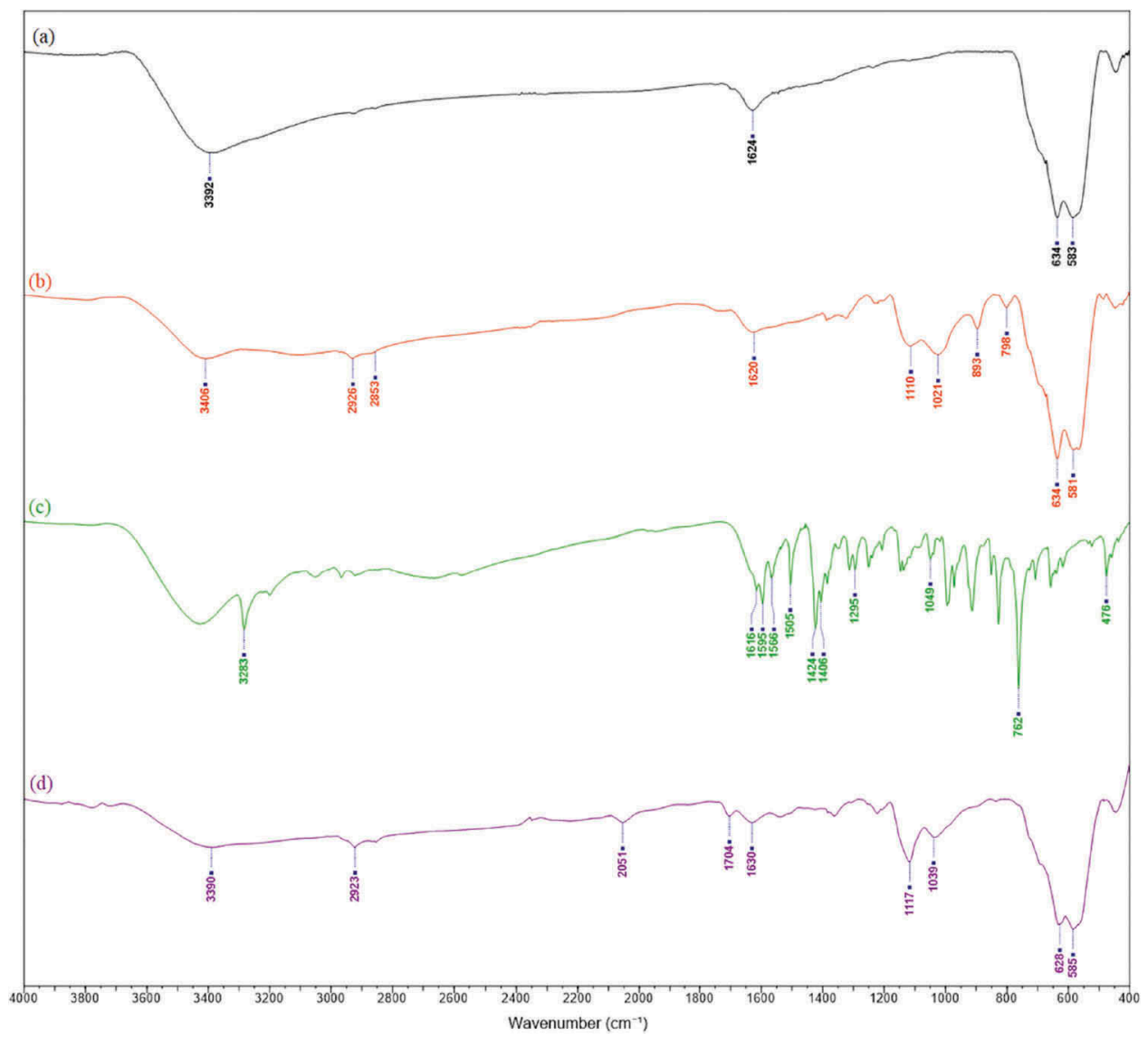

Figure 2. FT-IR spectra of (a) MNP- $\mathrm{Fe}_{3} \mathrm{O}_{4}$, (b) MNP-APTES, (c) SQ2MDTC, and (d) MNP SQ2MDTC.

assigned to $C-C$ stretching vibrations. Bands at 1595 and $1616 \mathrm{~cm}^{-1}$ were attributed as $\mathrm{C}=\mathrm{C}$ stretching bonds. The medium bands at 1505 and $1295 \mathrm{~cm}^{-1}$ were assigned to $\mathrm{C}=$ $\mathrm{N}$ and $\mathrm{C}-\mathrm{N}$ stretching modes, respectively.

Following the functionalisation of MNP-APTES with SQ2MDTC ligand, the resultant product showed two new prominent bands at 2051 and $1704 \mathrm{~cm}^{-1}$ (Figure 2(d)), which both are assigned as the stretching vibrations of $C=N$. Other peaks were similar to the peaks in MNP-APTES spectrum. This indicates that the $\mathrm{NH}_{2}$ of the ligand has been successfully bonded to methyl group of APTES. These results confirmed that the MNPSQ2MDTC has been successfully synthesised.

\subsubsection{X-ray diffraction analysis}

$\mathrm{XRD}$ is a powerful instrument for recognition of crystalline structure of synthesised

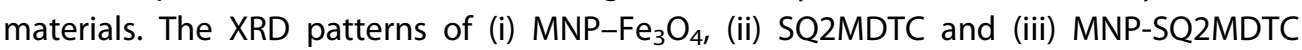
were depicted in Figure $3(\mathrm{a})$. The $2 \theta$ peaks at $30.1^{\circ}, 35.4^{\circ}, 43.1^{\circ}, 52.8^{\circ}, 57.3^{\circ}$ and $63.3^{\circ}$ corresponded indicating (220), (311), (400), (422), (511) and (440), respectively. The position and relative intensities of all diffraction signals of the both samples matched well with the characteristic peaks of standard pattern of standard iron oxide $\left(\mathrm{Fe}_{3} \mathrm{O}_{4}\right)$ diffraction data 


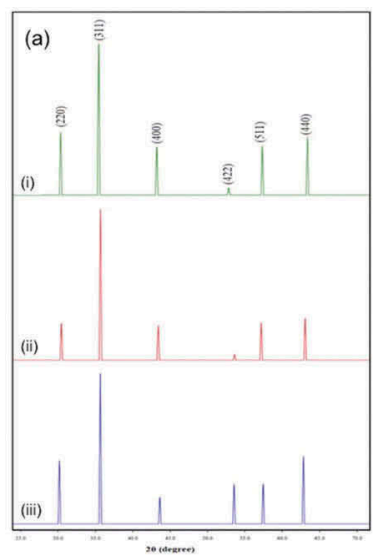

(c)
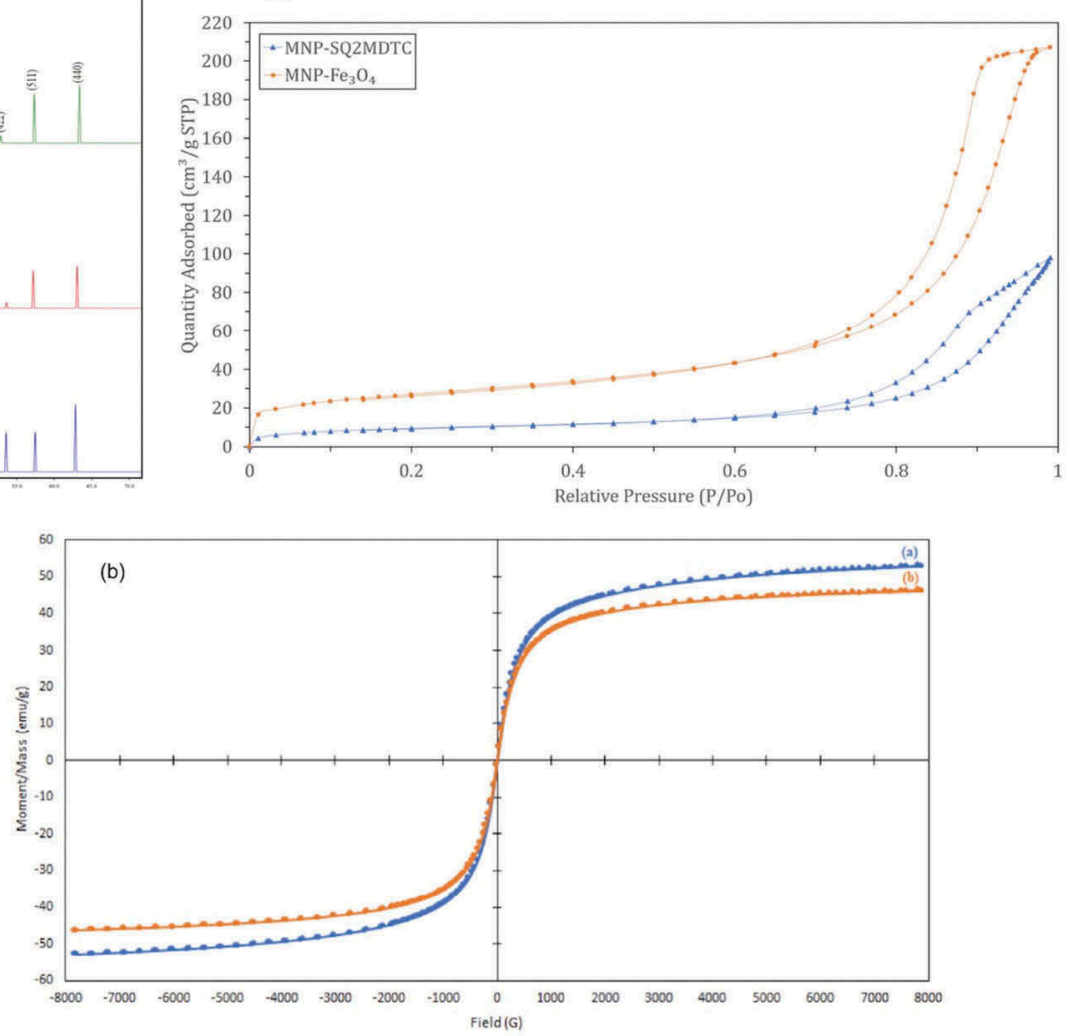

Figure 3. (a) XRD patterns of (i) MNP- $\mathrm{Fe}_{3} \mathrm{O}_{4}$, (ii) MNP-APTES, and (iii) MNP-SQ2MDTC, (b) Hysteresis loops of (i) MNP- $\mathrm{Fe}_{3} \mathrm{O}_{4}$ and (ii) MNP-SQ2MDTC and (c) $\mathrm{N}_{2}$ adsorption isotherms of MNP- $\mathrm{Fe}_{3} \mathrm{O}_{4}$ and MNP-SQ2MDTC.

(ICSD No. 01-075-0449). These results indicated that the immobilisation process did not change the magnetic crystalline profile as reported in several literatures [45,46]. It was also revealed that the synthesised materials have cubic spine structures.

\subsubsection{Vibrating sample magnetometry analysis}

Strong magnetisation is of great importance for the separation of target analytes through MSPE process. To investigate the magnetic properties of synthesised materials, the hysteresis loops were measured with a VSM. Figure 3(b) shows the magnetisation curves of $\mathrm{MNP}-\mathrm{Fe}_{3} \mathrm{O}_{4}$ and MNP-SQ2MDTC. No hysteresis was observed in the hysteresis loops of both materials and the remanence and coercivity were nearly zero, exhibiting typical superparamagnetic behaviour. It is crucial for magnetic nanoparticles to have superparamagnetic property to prevent aggregation and allow the nanoparticles to re-disperse rapidly when the magnetic field was removed [47]. The saturation magnetisation $\left(M_{s}\right)$ of MNP- $\mathrm{Fe}_{3} \mathrm{O}_{4}$ and MNP-SQ2MDTC were $52.985 \mathrm{emu} / \mathrm{g}$ and $46.353 \mathrm{emu} / \mathrm{g}$, respectively. MNP-SQ2MDTC has lower saturation magnetisation than the bare MNP. This indicates that the size of MNP-SQ2MDTC has increased due to the coating of silica and the 
SQ2MDTC. As MNP-SQ2MDTC has high $M_{s}$ (compared to the minimum of $16.3 \mathrm{emu} / \mathrm{g}$ ) [10], it can be easily collected by permanent magnets in a very short time duration.

\subsubsection{Brunauer-Emmett-Teller (BET) analysis}

The $\mathrm{N}_{2}$ adsorption isotherms of $\mathrm{MNP}-\mathrm{Fe}_{3} \mathrm{O}_{4}$ and MNP-SQ2MDTC are depicted in Figure 3(c). The samples exhibit type IV isotherms and a typical adsorption isotherm with $\mathrm{H} 1$ hysteresis, according to the IUPAC classification, associated with the presence of mesopores. The $p / p_{0}$ position of the inflection greater than 0.8 , indicates the structural (porous) characteristic and the sharpness of the step indicates the uniformity of the mesopore size distribution [48].

Based on BJH pore size distribution, the synthesised MNP-SQ2MDTC was mesoporous material with the specific surface area was found to be $33.52 \mathrm{~m}^{2} / \mathrm{g}$, total pore volume of $0.144 \mathrm{~cm}^{3} / \mathrm{g}$ and mean pore diameter of $17.22 \mathrm{~nm}$. The effective attachment of SQ2MDTC in the MNP-APTES pores is evidenced by the expressive reduction of the surface area and pore volume [48], as presented in Table 1. The binding of significant amount of SQ2MDTC on MNP-APTES altered the textural morphologies; it means that the SQ2MDTC may occupy a volume inside the pores of the silica nanocomposite and, as a result, a decrease in the pore volume was observed.

\subsubsection{FESEM analysis}

The morphology of the synthesised $\mathrm{MNP}-\mathrm{Fe}_{3} \mathrm{O}_{4}$ and MNP-SQ2MDTC were examined by using FESEM analysis. Figure 4 reveals that both materials have uniform spherical morphology and homogeneous particle size distribution. It can be seen that most of the particles formed were nanometre-sized where $\mathrm{MNP}-\mathrm{Fe}_{3} \mathrm{O}_{4}$ has an average diameter of about $17 \mathrm{~nm}$ and MNP-SQ2MDTC has an average diameter of $35 \mathrm{~nm}$. The size increment may be due to the addition of SQ2MDTC ligand on the surface of MNP.

\subsubsection{TEM analysis}

Transmission electron microscopes (TEM) is a powerful instrument which generates highly magnified image by employing a high voltage electron beam through the specimen. Therefore, it has been used for analysis of particle shapes and morphologies. Figure 4(c-d) shows the TEM micrographs of $\mathrm{MNP}-\mathrm{Fe}_{3} \mathrm{O}_{4}$ and MNP-SQ2MDTC. It can be seen that both nanomaterials have almost uniform and distinguishable polygonal shapes. However, MNP-SQ2MDTC appears darker compared to $\mathrm{MNP}-\mathrm{Fe}_{3} \mathrm{O}_{4}$, which indicates MNPSQ2MDTC has a higher density than $\mathrm{MNP}-\mathrm{Fe}_{3} \mathrm{O}_{4}$ [49]. Both $\mathrm{MNP}-\mathrm{Fe}_{3} \mathrm{O}_{4}$ and $\mathrm{MNP}$ SQ2MDTC also exhibit relatively good monodispersity. The average diameter of MNP- $\mathrm{Fe}_{3} \mathrm{O}_{4}$ and MNP-SQ2MDTC are $11.25 \mathrm{~nm}$ and $13.71 \mathrm{~nm}$, respectively. It is common for the coated MNP to have the increment of diameter in the range of $0-5 \mathrm{~nm}$ compared to the naked MNP [50] and MNP-SQ2MDTC has a bigger size due to the attachment of SQ2MDTC ligand on the surface of MNP.

Table 1. BET surface area of MNP- $\mathrm{Fe}_{3} \mathrm{O}_{4}$ and MNP-SQ2MDTC.

\begin{tabular}{lcc}
\hline & $\mathrm{MNP} \mathrm{Fe}_{3} \mathrm{O}_{4}$ & MNP-SQ2MDTC \\
\hline BET specific surface area $\left(\mathrm{m}^{2} / \mathrm{g}\right)$ & 94.8458 & 33.5171 \\
Mean pore volume $\left(\mathrm{cm}^{3} / \mathrm{g}\right)$ & 0.319 & 0.144 \\
Mean pore diameter $(\mathrm{nm})$ & 13.4907 & 17.2217 \\
\hline
\end{tabular}



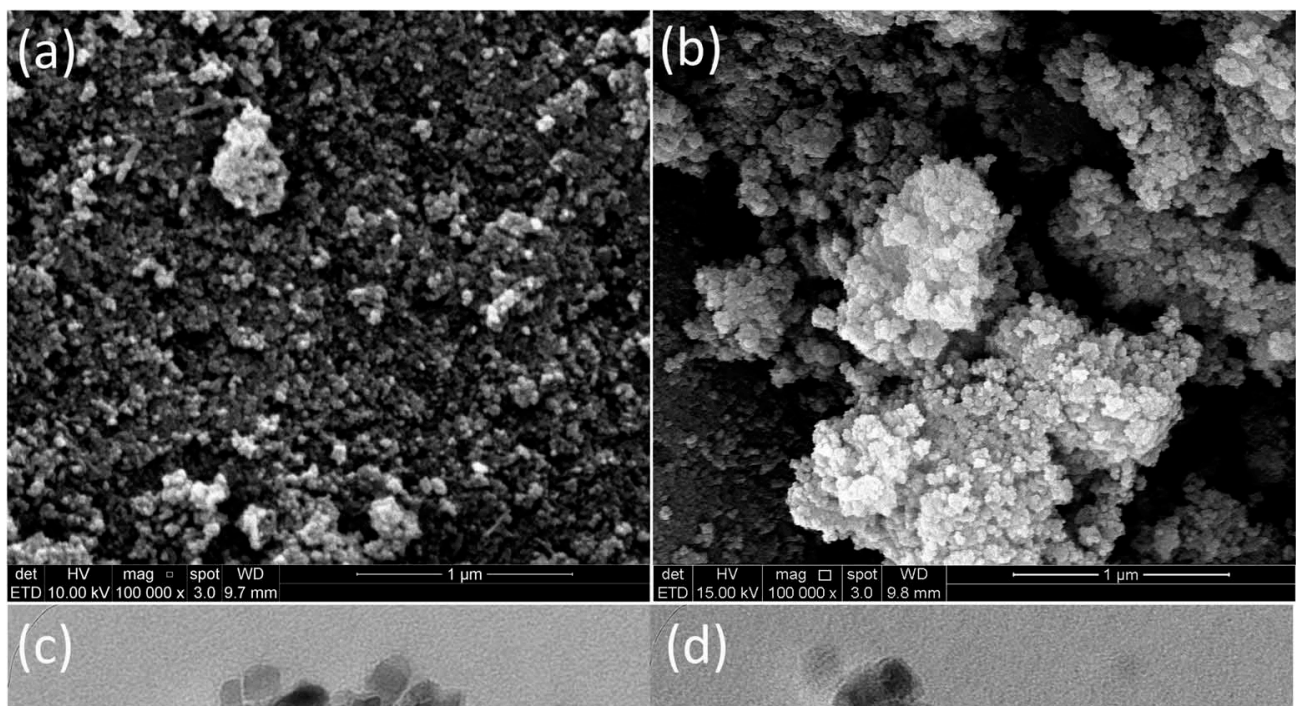

(d)

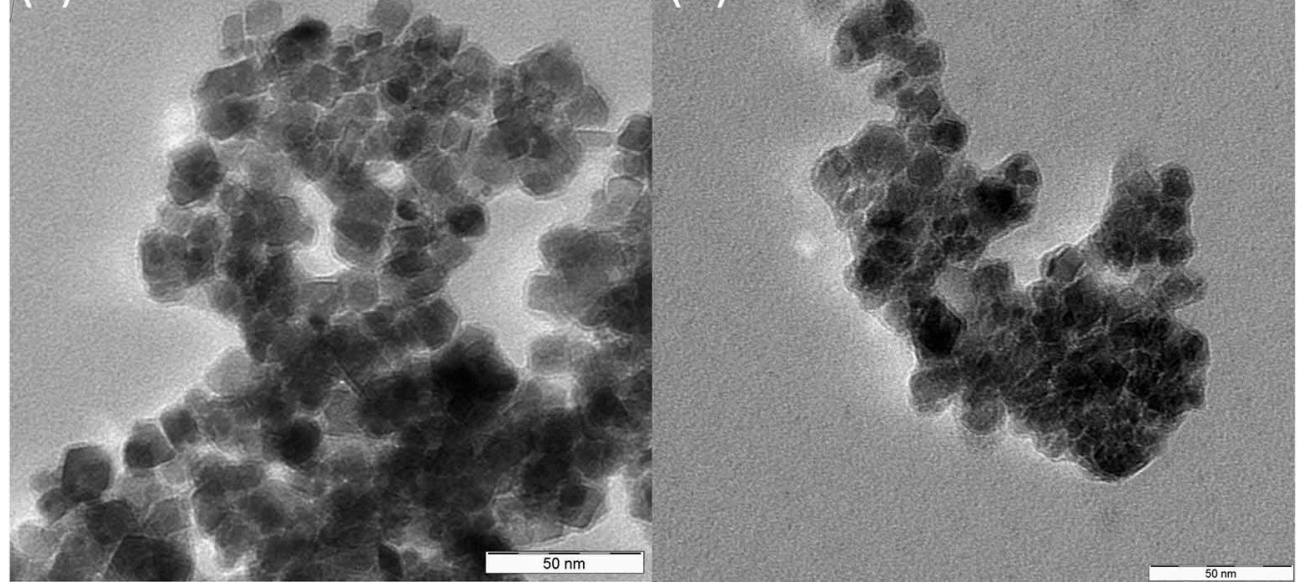

Figure 4. SEM images of (a) MNP- $\mathrm{Fe}_{3} \mathrm{O}_{4}$ and (b) MNP-SQ2MDTC, TEM micrographs of (c) MNP- $\mathrm{Fe}_{3} \mathrm{O}_{4}$ and (d) MNP-SQ2MDTC.

\subsection{Optimisation of parameters affecting MSPE procedure}

\subsubsection{Sample $p H$}

The aqueous $\mathrm{pH}$ has a vital role in the MSPE as it could enhance the efficiency of heavy metals adsorption, influencing surface chemistry, reduce interference from the matrix, determining the adsorbent surface charge and the degree of ionisation and speciation of the adsorbed metal ions [51-53]. The effect of $\mathrm{pH}$ on the adsorption percentage of metal ions was studied with $\mathrm{pH}$ varying from 3 to 6 . The $\mathrm{pH}$ was adjusted by utilising diluted acid or base $(0.1 \mathrm{M} \mathrm{HCl}$ or $0.1 \mathrm{M} \mathrm{NaOH})$. As could be seen from Figure $5(\mathrm{a})$, the quantitative adsorption for both $\mathrm{Cd}^{2+}$ and $\mathrm{Cu}^{2+}$ were increased gradually from low $\mathrm{pH}$ and reach maximum (>90\%) at $\mathrm{pH} 6$. This may due to the competition of metal ions and hydrogen ions to attach at binding site at low pH levels (i.e. pH 2-3) [10]. In contrast, more metal ions are binded to the adsorbent and successfully extracted from water at higher $\mathrm{pH}$ (i.e. $\mathrm{pH}$ 6). Moreover, in acidic media, the structure of the attached SQ2MDTC ligand might have 


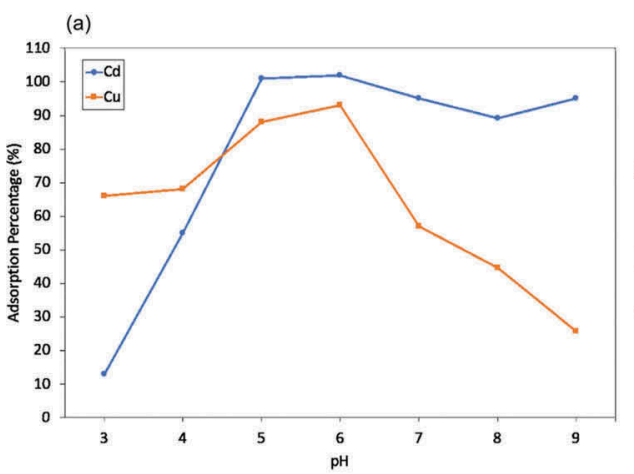

(c)

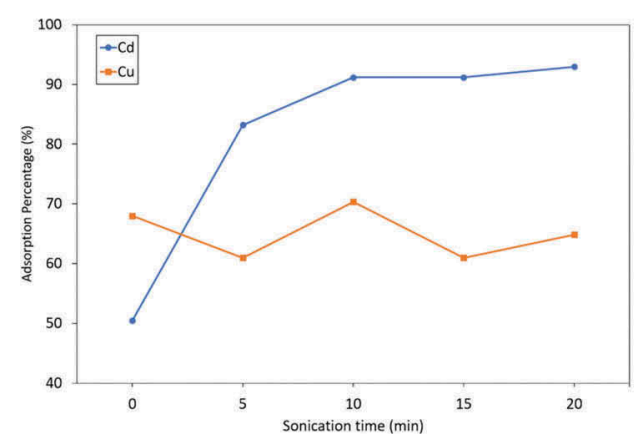

(b)

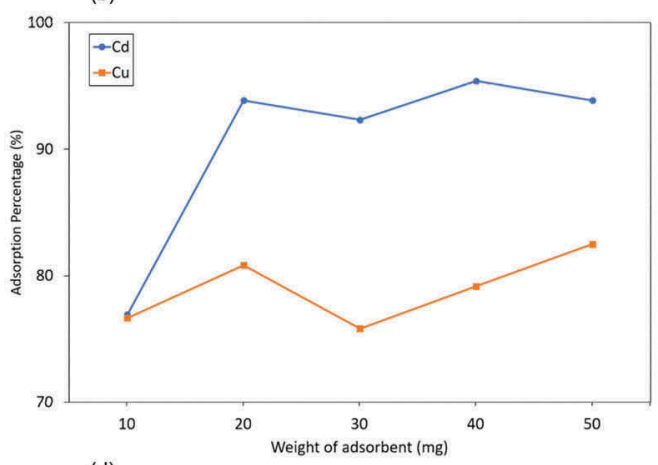

(d)

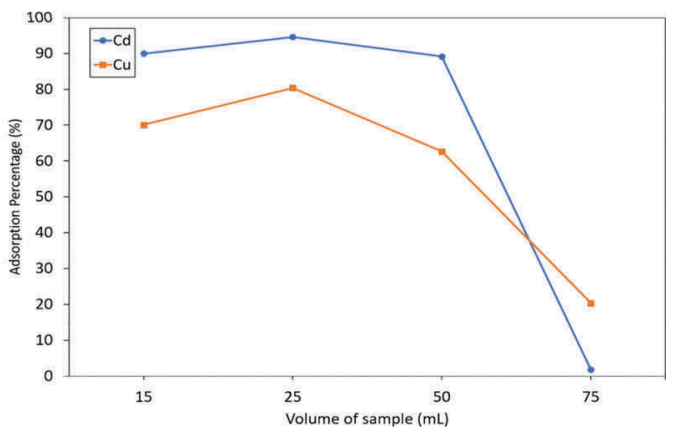

Figure 5. Effect of (a) pH (b) adsorbent weight (c) sonication time and (d) volume of sample on the adsorption percentage of $\mathrm{Cd}^{2+}$ and $\mathrm{Cu}^{2+}$ ions. MSPE conditions: $\mathrm{Cd}^{2+}$ and $\mathrm{Cu}^{2+}$ ions concentration: $100 \mu \mathrm{g} \mathrm{L}^{-1}$, sonication time for adsorption: $5 \mathrm{~min}$; desorption eluent: $\mathrm{HCl}$, volume of eluent: $5 \mathrm{~mL}$, sonication time for desorption: $10 \mathrm{~min}$.

been affected, where the nitrogen atoms could be protonated and the $\mathrm{S}-\mathrm{H}$ group could be oxidised, resulting in instability and incomplete formation of ligand-metal ion complex [54-56]. Conversely, the precipitation of metal ions as hydroxides could happen at high alkaline $\mathrm{pH}$ value beyond a $\mathrm{pH}$ of $6[10,57]$. The complexes between adsorbent and metal ions unlikely to be formed; hence, the preconcentration on the adsorbent is not favoured [58]. Considering this reason, extraction of metal ions at $\mathrm{pH}$ above 6 was not studied further. Hence, $\mathrm{pH} 6$ was selected for all subsequent experiments in this work.

\subsubsection{Weight of adsorbent}

Nanoparticles have significantly higher surface area and shorter diffusion route compared with other sorbents. These can result in high extraction efficiency and fast extraction dynamics [59]. Thus, satisfactory results with less adsorbent can be achieved with these sorbents. In order to investigate the optimum amount of adsorbent needed for the extraction of target analytes, the amount of MNP-SQ2MDTC adsorbent was varied from 10 to $50 \mathrm{mg}$. Based on the results obtained (Figure 5(b)), it can be seen that the high percentage of adsorption for adsorbent weight more than $20 \mathrm{mg}\left(75-80 \%\right.$ for $\mathrm{Cu}^{2+}$ and 92-95\% for $\mathrm{Cd}^{2+}$ ). Thus, $20 \mathrm{mg}$ was selected as optimum weight and utilised for the subsequent analysis. 


\subsubsection{Adsorption sonication time}

The duration of sonication during adsorption process was varied to determine the optimum reaction time and minimalise the required time to process each sample. Different sonication time for adsorption was investigated at 0, 5, 10, 15 and $20 \mathrm{~min}$. As depicted in Figure 5(c), 10 min provided the highest adsorption percentage of $\mathrm{Cd}^{2+}$ and $\mathrm{Cu}^{2+}$. As the sonication time increased to $20 \mathrm{~min}$, there is no significant increment for $\mathrm{Cd}^{2+}$. Thus, $10 \mathrm{~min}$ was employed during adsorption process.

\subsubsection{Sample volume}

The maximum applicable sample volume should be determined to explore the probability of enriching low concentration of analyte from large volume. The sample volume of $15,25,50,75$ and $100 \mathrm{~mL}$ were tested for this purpose. As shown in Figure 5(d), the best results were given by sample volume of $25 \mathrm{~mL}$ which are $80.37 \%\left(\mathrm{Cu}^{2+}\right)$ and $94.57 \%$ $\left(\mathrm{Cd}^{2+}\right)$. Thus, $25 \mathrm{~mL}$ was chosen as the optimum sample volume.

\subsubsection{Type and volume of eluent}

In order to achieve high enrichment factor, desorption solvents were varied for the desorption studies. Different acidic mediums were tested as they are more favourable for metal ions desorption [10]. The result is shown in Figure 6(a) indicated that $1 \mathrm{M}$ perchloric acid $\left(\mathrm{HClO}_{4}\right)$ was efficient as the desorption eluent for both $\mathrm{Cu}^{2+}$ and $\mathrm{Cd}^{2+}$. Moreover, metals like $\mathrm{Cu}^{2+}$ and $\mathrm{Cd}^{2+}$ are effectively desorbed with a strong acid [60,61], and $\mathrm{HClO}_{4}$ is one of the strongest Brønsted-Lowry acids where its $\mathrm{p} K_{\mathrm{a}}$ value $(<-10)$ is the lowest among the acid tested. Therefore, $\mathrm{HClO}_{4}$ has been adopted as eluent. The effect of $\mathrm{HClO}_{4}$ volume was investigated in the range of $0.5-30 \mathrm{~mL}$. Based on the results in Figure $6(\mathrm{~b})$, the $\mathrm{HClO}_{4}$ volume of $0.5 \mathrm{~mL}$ gives the best result and was the lowest volume for the desorption process. Thus, a volume of $0.5 \mathrm{~mL}$ of $1 \mathrm{M} \mathrm{HClO}_{4}$ was selected for the next procedure.

\subsubsection{Desorption sonication time}

The desorption times are also important for the recovery of $\mathrm{Cu}^{2+}$ and $\mathrm{Cd}^{2+}$ using MNPSQ2MDTC adsorbent. Sonication method was deployed to aid the desorption process. Hence, the duration of sonication was varied from 5 to $15 \mathrm{~min}$ to determine the most optimised time. Experimental results (Figure 6(c)) shows that a good recovery was obtained at 5 to $10 \mathrm{~min}$. Hence, it can be concluded that $5 \mathrm{~min}$ are sufficient enough to achieve the maximum recovery.

\subsection{Analytical performance}

Under the optimised experimental conditions, the newly synthesised MSPE adsorbent showed good linearity in the calibration range of $0.1-5.0 \mu \mathrm{g} \mathrm{mL}^{-1}$, with coefficient of determination $\left(\mathrm{R}^{2}\right)$ of 0.9952 and 0.9964 for $\mathrm{Cd}^{2+}$ and $\mathrm{Cu}^{2+}$, respectively. The limit of detection (LOD) for extraction of $\mathrm{Cd}^{2+}$ and $\mathrm{Cu}^{2+}$ were found to be 0.207 and 0.019 $\mu \mathrm{g} \mathrm{mL}^{-1}$, and their limit of quantification (LOQ) were 0.690 and $0.064 \mu \mathrm{g} \mathrm{mL}^{-1}$, respectively. The intra-day RSD of $\mathrm{Cd}^{2+}$ and $\mathrm{Cu}^{2+}$ were $3.01 \%$ and $1.48 \%$, and the inter-day RSD of $\mathrm{Cd}^{2+}$ and $\mathrm{Cu}^{2+}$ were $4.54 \%$ and $0.66 \%$, respectively. Table 2 summarises the analytical performance of the established method. Table 2 summarises the analytical performance of the established method. 
(a)

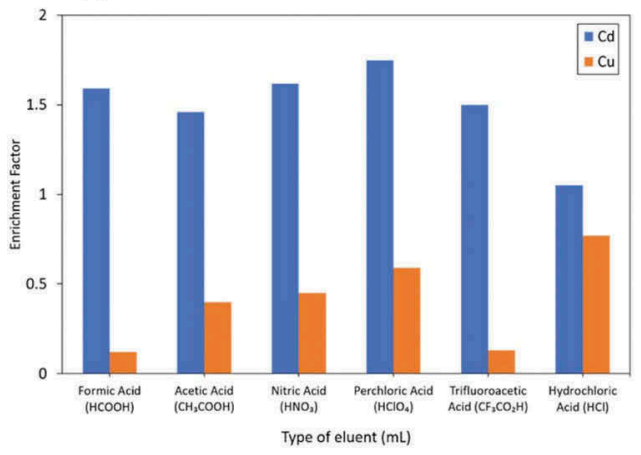

(b)

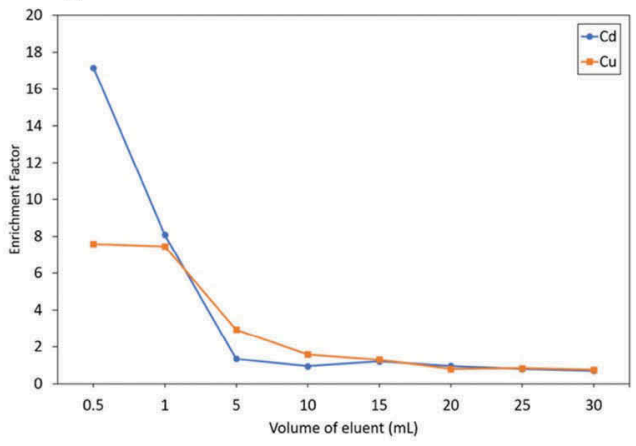

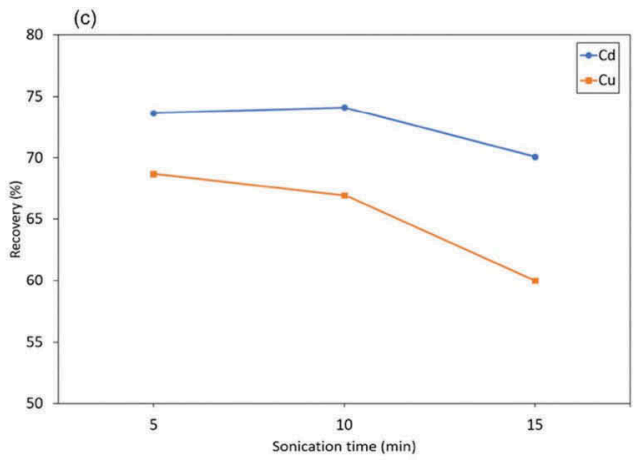

Figure 6. Effect of (a) different type of eluent (b) eluent volume on enrichment factors of $\mathrm{Cd}^{2+}$ and $\mathrm{Cu}^{2+}$ ions on enrichment factor and (c) desorption sonication time on the recovery percentage of $\mathrm{Cd}^{2+}$ and $\mathrm{Cu}^{2+}$ ions. MSPE conditions: $\mathrm{Cd}^{2+}$ and $\mathrm{Cu}^{2+}$ ions concentration: $100 \mu \mathrm{g} \mathrm{L}^{-1}$, volume of sample: $25 \mathrm{~mL}$, pH: 6 , sonication time for adsorption: $10 \mathrm{~min}$, mass of adsorbent: $20 \mathrm{mg}$.

Table 2. Validation parameters for the proposed method for $\mathrm{Cd}^{2+}$ and $\mathrm{Cu}^{2+}$.

\begin{tabular}{lcccccc}
\hline Analytes & $\begin{array}{c}\text { Linearity range } \\
\left(\mu \mathrm{g} \mathrm{m}^{-1}\right)\end{array}$ & $\begin{array}{c}\text { coefficient of } \\
\text { determination }\left(\mathrm{R}^{2}\right)\end{array}$ & $\begin{array}{c}\text { LOD } \\
\left(\mu \mathrm{g} \mathrm{mL}^{-1}\right)\end{array}$ & $\begin{array}{c}\text { LOQ } \\
\left(\mu \mathrm{g} \mathrm{mL}^{-1}\right)\end{array}$ & $\begin{array}{c}\text { Intra-day RSD } \\
(\%, n=6)\end{array}$ & $\begin{array}{c}\text { Inter-day RSD } \\
(\%, n=3)\end{array}$ \\
\hline $\mathrm{Cd}^{2+}$ & $0.1-5.0$ & 0.995 & 0.054 & 0.180 & 3.01 & 4.54 \\
$\mathrm{Cu}^{2+}$ & $0.1-5.0$ & 0.996 & 0.040 & 0.134 & 1.48 & 0.66 \\
\hline
\end{tabular}

\subsection{Analytical application on real sample}

In order to evaluate the accuracy and applicability, the proposed extraction method has been applied in environmental samples for the determination of $\mathrm{Cd}^{2+}$ and $\mathrm{Cu}^{2+}$ speciation. The analytical results along with the recoveries for the unspiked and spiked samples with known concentration are listed in Table 3. It can be seen from the obtained results that the overall recoveries for $\mathrm{Cd}^{2+}$ were in the range of $75.6 \%$ to $93.9 \%$, while for $\mathrm{Cu}^{2+}$, the recoveries ranged from $81.5 \%$ to $98.7 \%$ for $\mathrm{Cu}^{2+}$. The recoveries of both analytes obtained RSD values lower than $0.68 \%$ for both $\mathrm{Cd}^{2+}$ and $\mathrm{Cu}^{2+}$, which indicated a precise method.

\subsection{Method performance comparison}

The performance of developed MSPE method has been reviewed by a comparison with other reported preconcentration techniques in literature, as summarised in Table 4. It 
Table 3. Analytical results for determination of cadmium and copper in different water samples (mean $\pm \mathrm{SD}, n=3$ ) using the MSPE procedure.

\begin{tabular}{|c|c|c|c|c|}
\hline Sample & Element & Added $\left(\mu \mathrm{g} \mathrm{mL}^{-1}\right)$ & Found $\left(\mu \mathrm{gL}^{-1}\right)$ & Recovery (\%) \\
\hline \multirow[t]{4}{*}{ River 1} & $\mathrm{Cu}$ & 0 & $0.662 \pm 0.002$ & - \\
\hline & & 0.1 & $0.710 \pm 0.002$ & 93.2 \\
\hline & $\mathrm{Cd}$ & 0 & $0.120 \pm 0.002$ & - \\
\hline & & 1.0 & $1.028 \pm 0.002$ & 91.9 \\
\hline \multirow{4}{*}{ River 2} & $\mathrm{Cu}$ & 0 & $0.676 \pm 0.002$ & \\
\hline & & 0.1 & $0.766 \pm 0.001$ & 98.7 \\
\hline & $\mathrm{Cd}$ & 0 & $0.119 \pm 0.002$ & 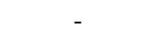 \\
\hline & & 1.0 & $0.946 \pm 0.006$ & 84.5 \\
\hline \multirow[t]{4}{*}{ River 3} & $\mathrm{Cu}$ & 0 & $0.334 \pm 0.003$ & - \\
\hline & & 0.1 & $0.636 \pm 0.003$ & 82.8 \\
\hline & $\mathrm{Cd}$ & 0 & $0.124 \pm 0.001$ & - \\
\hline & & 1.0 & $1.055 \pm 0.005$ & 93.9 \\
\hline \multirow[t]{4}{*}{ River 4} & $\mathrm{Cu}$ & 0 & $0.376 \pm 0.005$ & - \\
\hline & & 0.1 & $0.694 \pm 0.002$ & 81.5 \\
\hline & $\mathrm{Cd}$ & 0 & $0.120 \pm 0.001$ & - \\
\hline & & 1.0 & $0.973 \pm 0.004$ & 86.9 \\
\hline \multirow[t]{4}{*}{ River 5} & $\mathrm{Cu}$ & 0 & $0.630 \pm 0.001$ & - \\
\hline & & 0.1 & $0.706 \pm 0.000$ & 96.7 \\
\hline & $\mathrm{Cd}$ & 0 & $0.116 \pm 0.002$ & - \\
\hline & & 1.0 & $0.844 \pm 0.004$ & 75.6 \\
\hline
\end{tabular}

Table 4. Method performance comparison for determination of $\mathrm{Cd}^{2+}$ and $\mathrm{Cu}^{2+}$ in various sample matrices.

\begin{tabular}{|c|c|c|c|c|}
\hline Pretreatment technique & Sample matrix & Analyte & $\begin{array}{c}\text { LOD } \\
\left(\mu \mathrm{g} \mathrm{m}^{-1}\right)\end{array}$ & Reference \\
\hline $\begin{array}{l}\text { Ionic liquid based dispersive liquid- } \\
\text { liquid microextraction (IL-DLLME) }\end{array}$ & $\begin{array}{l}\text { Sea water, lake water, stream water, } \\
\text { tap water }\end{array}$ & $\mathrm{Cu}$ & 0.81 & [62] \\
\hline $\begin{array}{l}\text { Ultrasound-assisted emulsification } \\
\text { solidified floating organic drop } \\
\text { microextraction (USAE-SFODME) }\end{array}$ & Drinking water, sea water, river water & $\mathrm{Cu}$ & 0.76 & [63] \\
\hline Cloud-point extraction (CPE) & Mineral water, tap water, sea water & $\mathrm{Cd}$ & 0.15 & [64] \\
\hline Solid phase extraction (SPE) & Leakage water, tap water, drain water & $\mathrm{Cd}$ & 0.0 & [65] \\
\hline $\begin{array}{l}\text { Magnetic solid phase microextraction } \\
\text { (MSPME) }\end{array}$ & Sugar can spirit & $\begin{array}{l}\mathrm{Cu} \\
\mathrm{Cd}\end{array}$ & $\begin{array}{l}0.032 \\
0.038\end{array}$ & [66] \\
\hline $\begin{array}{l}\text { Magnetic solid phase extraction } \\
\text { (MSPE) }\end{array}$ & Water & $\begin{array}{l}\mathrm{Cu} \\
\mathrm{Cd}\end{array}$ & $\begin{array}{l}0.040 \\
0.054\end{array}$ & This work \\
\hline
\end{tabular}

was evident that the proposed method in the current work produced acceptable results and in the range with other methods. Liquid phase microextraction methods including ionic liquid-based dispersive liquid-liquid microextraction (IL-DLLME) and ultrasoundassisted emulsification solidified floating organic drop microextraction (USAE-SFODME) have been developed recently to remove $\mathrm{Cu}$ from water, but they produced higher LODs compared to the presented MSPE method. Vatankhah et al. [64] opted for a greener method which is cloud point extraction (CPE) for the separation and preconcentration of cadmium and lead ions, but the LOD obtained of cadmium is two times higher than this reported work. The traditional solid phase extraction (SPE) method also has been used recently by Topuz, Kabadayi and Solmaz [65] for determination of several heavy metals including $C d$, where they obtained a slightly higher LOD than current method. However, SPE technique is known to have several disadvantages including tedious steps, requires costly extraction device, and usually having column blockage and high back pressure problems. A new miniaturised technique called magnetic solid phase microextraction (MSPME) has been applied by Meira et al. [66] 
for the determination of $\mathrm{Cu}, \mathrm{Cd}, \mathrm{Pb}$ and $\mathrm{V}$ in Brazilian sugarcane spirit. This method obtained LOD lower than the MSPE method proposed in this report, but the procedure is time consuming as drying process at ambient temperature is required after extraction prior instrument analysis. The reusability of the material is also questionable as no desorption process proposed. Generally, the MNP-SQ2MDTC-based MSPE we propose has a good performance with a relatively low LOD, along with several eminent merits including simple and rapid extraction, cost effective and high efficiency.

\section{Conclusion}

The new MNP functionalised with S-quinolin-2-yl-methyldithiocarbazate (MNP-SQ2MDTC) were successfully synthesised and developed as an adsorbent to remove $\mathrm{Cd}^{2+}$ and $\mathrm{Cu}^{2+}$ from aqueous samples prior to determination using ICP-OES. The MNP-SQ2MDTC-based MSPE has a high adsorption capacity, a better sensitivity, and good accuracy and precision. It has the potential to be applied in the removal of $\mathrm{Cd}^{2+}$ and $\mathrm{Cu}^{2+}$ in the environmental waters. It also provides a simple and rapid extraction for heavy metals.

\section{Disclosure statement}

No potential conflict of interest was reported by the authors.

\section{Funding}

This work was supported by funding from Universiti Sains Malaysia Research Grants (Short Term: 304.PKIMIA.6313334; Bridging: 304.PKIMIA.6316492) and International Islamic University Malaysia Research Initiative Grants (RIGS15-136-0136, P-RIGS18-029-0029).

\section{ORCID}

Noorfatimah Yahaya (iD) http://orcid.org/0000-0002-3079-7837

\section{References}

[1] S. Chowdhury, M.A.J. Mazumder, O. Al-Attas and T. Husain, Sci. Total Environ. 476, 569 (2016).

[2] J. Xu, Z. Cao, Y. Zhang, Z. Yuan, Z. Lou, X. Xu and X. Wang, Chemosphere 195, 351 (2018). doi:10.1016/j.chemosphere.2017.12.061.

[3] A.I.A. Sherlala, A.A.A. Raman, M.M. Bello and A. Asghar, Chemosphere 193, 1004 (2018). doi:10.1016/j.chemosphere.2017.11.093.

[4] I. Ali, Chem. Rev. 112, 5073 (2012). doi:10.1021/cr300133d.

[5] Y.J. Acosta-Silva, R. Nava, V. Hernández-Morales, S.A. Macías-Sánchez, M.L. Gómez-Herrera and B. Pawelec, Appl. Catal. B Environ. 110, 108 (2011). doi:10.1016/j.apcatb.2011.08.032.

[6] W. Xie and X. Zang, Food Chem. 194, 1283 (2016). doi:10.1016/j.foodchem.2015.09.009.

[7] S.N.A. Baharin, N. Muhamad Sarih, S. Mohamad, S. Shahabuddin, K. Sulaiman, A. Ma'Amor, N. M. Sarih, S. Mohamad, N.N.M. Zain, N.K. Abu Bakar and S. Mohamad, Polymers (Basel) 8, 653 (2016). doi:10.3390/polym8050117.

[8] M. Safarikova, I. Kibrikova, L. Ptackova, T. Hubka, K. Komarek, I. Safarik and J. Magn, Magn. Mater 293, 377 (2005). doi:10.1016/j.jmmm.2005.02.034. 
[9] Z. Es'haghi and E. Esmaeili-Shahri, J. Chromatogr. B 973, 142 (2014). doi:10.1016/j. jchromb.2014.09.030.

[10] L.I. Abd Ali, W.A. Wan Ibrahim, A. Sulaiman, M.A. Kamboh and M.M. Sanagi, Talanta 148 (191) (2016). doi:10.1016/j.talanta.2015.10.062.

[11] Y. Liu, Y. Wang, Q. Dai and Y. Zhou, Anal. Chim. Acta 936, 168 (2016). doi:10.1016/j. aca.2016.07.003.

[12] S.-K. Li, F.-Z. Huang, Y. Wang, Y.-H. Shen, L.-G. Qiu, A.-J. Xie and S.-J. Xu, J. Mater. Chem. 21, 7459 (2011). doi:10.1039/c0jm04569a.

[13] Q. Peng, Y. Liu, G. Zeng, W. Xu, C. Yang and J. Zhang, J. Hazard. Mater 177, 676 (2010). doi:10.1016/j.jhazmat.2009.12.084.

[14] J. Ding, Q. Gao, D. Luo, Z.G. Shi and Y.Q. Feng, J. Chromatogr. A 1217, 7351 (2010). doi:10.1016/j.chroma.2010.09.074.

[15] E. Aliyari, M. Alvand and F. Shemirani, RSC Adv. 6, 64193 (2016). doi:10.1039/C6RA04163A.

[16] J.A. Rodriguez, J. Espinosa, K. Aguilar-Arteaga, I.S. Ibarra and J.M. Miranda, Microchim. Acta 171, 407 (2010). doi:10.1007/s00604-010-0428-8.

[17] I. Vasconcelos and C. Fernandes, TrAC - Trends Anal. Chem. 89, 41 (2017). doi:10.1016/j. trac.2016.11.011.

[18] K.M. Diniz and C.R.T. Tarley, Microchem. J. 123, 185 (2015). doi:10.1016/j.microc.2015.06.011.

[19] J. Ma, G. Wu, S. Li, W. Tan, X. Wang, J. Li and L. Chen, J. Chromatogr. A 1553, 57 (2018). doi:10.1016/j.chroma.2018.04.034.

[20] J. Ma, Z. Yao, L. Hou, W. Lu, Q. Yang, J. Li and L. Chen, Talanta 161, 686 (2016). doi:10.1016/j. talanta.2016.09.035.

[21] J. Ma, L. Jiang, G. Wu, Y. Xia, W. Lu, J. Li and L. Chen, J. Chromatogr. A 1466, 12 (2016). doi:10.1016/j.chroma.2016.08.065.

[22] J. Li, R. Dong, X. Wang, H. Xiong, S. Xu, D. Shen, X. Song and L. Chen, RSC Adv. 5, 10611 (2015). doi:10.1039/C4RA11177J.

[23] G. Wu, J. Ma, S. Li, J. Guan, B. Jiang, L. Wang, J. Li, X. Wang and L. Chen, J. Colloid Interface Sci. 528, 360 (2018). doi:10.1016/j.jcis.2018.05.105.

[24] A.R. Bagheri, M. Arabi, M. Ghaedi, A. Ostovan, X. Wang, J. Li and L. Chen, Talanta 195, 390 (2019). doi:10.1016/j.talanta.2018.11.065.

[25] X. Wu, X. Wang, W. Lu, X. Wang, J. Li, H. You, H. Xiong and L. Chen, J. Chromatogr. A 1435, 30 (2016). doi:10.1016/j.chroma.2016.01.040.

[26] W. Yang, T. Muhammad, A. Yigaimu, K. Muhammad and L. Chen, J. Sep. Sci. 41, 4185 (2018). doi:10.1002/jssc.201800797.

[27] P. Bera, C.H. Kim and S. II Seok, Polyhedron 27, 3433 (2008). doi:10.1016/j.poly.2008.07.039.

[28] F.C. Lima, T.S. Silva, C.H.G. Martins and C.C. Gatto, Inorganica Chim. Acta 483, 464 (2018). doi:10.1016/j.ica.2018.08.032.

[29] X.-Y. Qiu, C. Zhang, S.-Z. Li, G.-X. Cao, P. Qu, F.-Q. Zhang, J.-G. Ma and B. Zhai, Inorg. Chem. Commun. 46, 202 (2014). doi:10.1016/j.inoche.2014.05.015.

[30] -F.N.-F. How, D.J. Watkin, K.A. Crouse, M.I.M. Tahir and A. Crystallogr, Sect. E Struct. Reports Online 63, o3137 (2007). doi:10.1107/S1600536807024609.

[31] M.T.H. Tarafder, A.M. Ali, Y.W. Wong, S.H. Wong and K.A. Crouse, Synth. React. Inorg. Met. Chem. 31, 115 (2001). doi:10.1081/SIM-100001937.

[32] M.T.H. Tarafder, K.-B. Chew, K.A. Crouse, A.M. Ali, B.M. Yamin and H.-K. Fun, Polyhedron 21, 2683 (2002). doi:10.1016/S0277-5387(02)01285-8.

[33] E. Zangrando, M.T. Islam, M.A.A.A.A. Islam, M.C. Sheikh, M.T.H. Tarafder, R. Miyatake, R. Zahan and M.A. Hossain, Inorganica. Chim. Acta 427 (278) (2015). doi:10.1016/j.ica.2014.12.014.

[34] M.S. Begum, E. Zangrando, M.B.H. Howlader, M.C. Sheikh, R. Miyatake, M.M. Hossain, M. M. Alam and M.A. Hasnat, Polyhedron. 105 (56) (2016). doi:10.1016/j.poly.2015.11.046.

[35] R. Takjoo, R. Centore and S.S. Hayatolgheibi, Inorganica. Chim. Acta 471 (587) (2018). doi:10.1016/j.ica.2017.11.043.

[36] D.Z. Wang, S.F. Zhang, Y. Zhang and L. Lin, J. Proteomics. 132-140, 135 (2016).

[37] E.N.M. Yusof, T.B.S.A. Ravoof, J. Jamsari, E.R.T. Tiekink, A. Veerakumarasivam, K.A. Crouse, M.I. M. Tahir and H. Ahmad, Inorganica. Chim. Acta 438, 85 (2015). doi:10.1016/j.ica.2015.08.029. 
[38] -F.N.-F. How, K.A. Crouse, M.I.M. Tahir, M.T.H. Tarafder and A.R. Cowley, Polyhedron 27, 3325 (2008). doi:10.1016/j.poly.2008.07.022.

[39] A.B. Rode, J. Kim, S.-H. Kim, G. Gupta and I.S. Hong, Tetrahedron Lett. 53, 2571 (2012). doi:10.1016/j.tetlet.2012.03.040.

[40] H.R. Rajabi, H. Arjmand, S.J. Hoseini, H. Nasrabadi and J. Magn, Magn. Mater 394, 7 (2015). doi:10.1016/j.jmmm.2015.06.024.

[41] A. Mohammadi, M. Barikani and M.M. Lakouraj, Mater. Sci. Eng. C 66, 106 (2016). doi:10.1016/j. msec.2016.04.064.

[42] E.N.M. Yusof, N.M. Nasri, T.B.S.A. Ravoof and E.R.T. Tiekink, Molbank. 2019, 2 (2019).

[43] R.A. Bhat and D. Kumar, Res. Chem. Intermed. 45, 2565 (2019). doi:10.1007/s11 164-019-03752-0.

[44] A. Liopo, R. Su and A.A. Oraevsky, Photoacoustics 3 (35) (2015). doi:10.1016/j.pacs.2015.02.001.

[45] S. Sinniah, S. Mohamad and N.S.A. Manan, Appl. Surf. Sci. 357, 543 (2015). doi:10.1016/j. apsusc.2015.09.078.

[46] G. Giakisikli and A.N. Anthemidis, Anal. Chim. Acta 789, 1 (2013). doi:10.1016/j.aca.2013.04.021.

[47] Z.Y. Ma, Y.P. Guan, X.Q. Liu and H.Z. Liu, J. Appl. Polym. Sci. 96, 2174 (2005). doi:10.1002/ app.21688.

[48] K.C. de Souza, G.F. Andrade, I. Vasconcelos, I.M. de Oliveira Viana, C. Fernandes and E.M.B. de Sousa, Mater. Sci. Eng. C 40, 275 (2014). doi:10.1016/j.msec.2014.04.004.

[49] E. Alzahrani, Int. J. Anal. Chem. 2015 (2015). doi:10.1155/2015/797606

[50] W. Wu, Q. He and C. Jiang, Nanoscale Res. Lett. 3, 397 (2008).

[51] S.R. Chowdhury, E.K. Yanful and A.R. Pratt, J. Hazard. Mater 235-236, 246 (2012). doi:10.1016/ j.jhazmat.2012.07.054.

[52] M.A. Ahmed, S.M. Ali, S.I. El-Dek and A. Galal, Mater. Sci. Eng. B 178, 744 (2013). doi:10.1016/j. mseb.2013.03.011.

[53] S. Rajput, C.U. Pittman and D. Mohan, Colloid Interface Sci. 468, 334 (2016). doi:10.1016/j. jcis.2015.12.008.

[54] M.H. Mashhadizadeh, M. Pesteh, M. Talakesh, I. Sheikhshoaie, M.M. Ardakani and M.A. Karimi, Spectrochim. Acta - Part B At. Spectrosc. 63, 885 (2008). doi:10.1016/j.sab.2008.03.018.

[55] K. Alizadeh, R. Parooi, P. Hashemi, B. Rezaei and M.R. Ganjali, J. Hazard. Mater 186, 1794 (2011). doi:10.1016/j.jhazmat.2010.12.067.

[56] H. Bagheri, A. Afkhami, M. Saber-Tehrani and H. Khoshsafar, Talanta 97 (87) (2012). doi:10.1016/j.talanta.2012.03.066.

[57] G. Cheng, M. He, H. Peng and B. Hu, Talanta 88 (507) (2012). doi:10.1016/j.talanta.2011.11.025.

[58] A.E. Karatapanis, Y. Fiamegos and C.D. Stalikas, Talanta 84 (834) (2011). doi:10.1016/j. talanta.2011.02.013.

[59] A.B. Tabrizi, M.R. Rashidi and H. Ostadi, J. Braz. Chem. Soc. 25, 709 (2014).

[60] S.P. Mishra, Curr. Sci. 107, 601 (2014).

[61] W.J. Chen, L.C. Hsiao and K.K.Y. Chen, Process Biochem. 43, 488 (2008). doi:10.1016/j. procbio.2007.11.017.

[62] Y. Çağlar, E.T. Saka and J. Karbala Int, Mod. Sci. 3, 185 (2017).

[63] Q. Chang, J. Zhang, X. Du, J. Ma and J. Li, Front. Environ. Sci. Eng. China 4, 187 (2010). doi:10.1007/s11783-010-0030-7.

[64] G. Vatankhah, M. Ebrahimi and M. Kahani, Eurasian J. Anal. Chem. 12, 987 (2017). doi:10.12973/ejac.2017.00227a.

[65] B. Topuz, F. Kabadayi and A. Solmaz, Int. J. Environ. Anal. Chem. 99, 641 (2019). doi:10.1080/ 03067319.2019 .1607317$.

[66] L. Meira, J. Almeida, F. Dias and L. Teixeira, Brazilian J. Anal. Chem. 60-66, 6 (2019). 